\title{
Article
}

\section{Pharmacokinetic and pharmacodynamic evidence for developing an oral formulation of octreotide against gastric mucosal injury}

\author{
Xi-nuo LI\#, Tai RAO\#, Yang-fan XU, Kang-rui HU, Zhang-pei ZHU, Hao-feng LI, Dian KANG, Yu-hao SHAO, Bo-yu SHEN, \\ Xiao-xi YIN, Lin XIE, Guang-ji WANG*, Yan LIANG* \\ Key Lab of Drug Metabolism \& Pharmacokinetics, State Key Laboratory of Natural Medicines, China Pharmaceutical University, \\ Nanjing 210009, China
}

\begin{abstract}
Among the somatostatin analogues, octreotide (OCT) is the most commonly used in clinic via intravenous or subcutaneous injection to treat various diseases caused by increased secretion of growth hormone, gastrin or insulin. In order to assesse the feasibility of developing oral formulations of OCT, we conducted systematical pharmacokinetic and pharmacodynamic analyses of OCT in several animal models. The pharmacokinetic studies in rats showed that intragastric administration of OCT had extremely low bioavailability $(<0.5 \%)$, but it could specifically distribute to the gastric mucosa due to the high expression of somatostatin receptor 2 (SSTR2) in the rat stomach. The pharmacodynamic studies revealed that intragastric administration of OCT dose-dependently protected against gastric mucosal injury (GMI) in mice with WIRS-induced mouse gastric ulcers, which were comparable to those achieved by intravenous injection of OCT, and this effect was markedly attenuated by co-administration of CYN-154806, an antagonist of SSTR2. In pyloric ligation-induced ulcer mice, we further demonstrated that OCT significantly reduced the secretion of gastric acid via down-regulating the level of gastrin, which was responsible for the protective effect of OCT against GMI. Overall, we have provided pharmacokinetic and pharmacodynamic evidence for the feasibility of developing an oral formulation of OCT. Most importantly, the influence of SSTR2 on the pharmacokinetics and pharmacodynamics of OCT suggested that an oral formulation of OCT might be applicable for other clinical indications, including neuroendocrine neoplasms and pituitary adenoma due to the overexpression of SSTR2 on these tumor cells.
\end{abstract}

Keywords: somatostatin; somatostatin receptors 2; octreotide; CYN-154806; oral formulation; pharmacokinetics; pharmacodynamics; gastric mucosal injury; gastrin; gastric acid

Acta Pharmacologica Sinica (2018) 39: 1373-1385; doi: 10.1038/aps.2017.159; published online 30 Nov 2017

\section{Introduction}

Somatostatin (SST), a cyclic hormone-release inhibitory peptide produced by neuroendocrine, inflammatory, and immune cells, has high binding affinity to all five of its receptors (SSTR1, SSTR2, SSTR3, SSTR4 and SSTR5) and exhibits a wide range of physiological functions ${ }^{[1-3]}$. However, the efficacy of SST has been severely hindered by its short half-life $\left(t_{1 / 2}\right)$ in systemic circulation (plasma $t_{1 / 2}$ is approximately $3 \mathrm{~min}$ ). To overcome the limitations of SST, a series of somatostatin analogues, including OCT, lanreotide and vapreotide, has been designed over the past twenty years. OCT, a first-generation

\footnotetext{
\# These authors contributed equally to this work.

*To whom correspondence should be addressed.

E-mail liangyan0679@163.com (Yan LIANG); guangjiwang@hotmail.com (Guang-ji WANG)

Received 2017-08-12 Accepted 2017-10-18
}

synthesized somatostatin analogue with a longer $t_{1 / 2}$ than native SST, is efficacious in the treatment of upper gastrointestinal bleeding, hemorrhage of the lower digestive tract caused by tumors, acute gastric mucosal lesions and stress ulcer bleeding, acute pancreatitis, epidemic parotiditis, parenteral leakage and gastric cancer ${ }^{[4-9]}$. In 1988, a short-acting immediate-release formulation of OCT, clinically administered either subcutaneously or intravenously, initially received regulatory approval for the treatment of acromegaly in Europe ${ }^{[8,10]}$. In 1995, a long-acting OCT formulation (OCT LAR) was introduced and subsequently approved ${ }^{[11]}$. After a single injection of OCT LAR, OCT quickly reaches an initial peak within $1 \mathrm{~h}$ of administration and then progressively decays within $12 \mathrm{~h}$. Overall, the main clinical administration routes for OCT have included intravenous injection, subcutaneous injection and intramuscular injection, yet the burden of injectable drug regimens adversely impacts patient quality of life with chronic 
conditions.

Oral administration is regarded as the most favorable route of drug administration for several reasons, including ease of compliance, convenience, reduced toxicity, a simple production process and overall cost-effectiveness ${ }^{[12,13]}$. For OCT, the high molecular weight $\left(\mathrm{C}_{49} \mathrm{H}_{66} \mathrm{~N}_{10} \mathrm{O}_{10} \mathrm{~S}_{2}\right.$, MW 1019.3) makes it difficult for this drug to permeate through the intestinal wall, resulting in low bioavailability after oral administration. Over the past few decades, OCT has attracted a great deal of attention in terms of enhancement of its oral delivery efficiency via increasing its lipophilicity ${ }^{[14]}$, as well as transiently opening tight cell junctions by sinomenine ${ }^{[15]}$ or alkylsaccharides ${ }^{[16]}$ to increase paracellular absorption ${ }^{[14-17]}$. Although these attempts have improved the oral absorption of OCT to some extent, they have not yet robustly improved its bioavailability in vivo.

Based on the target site of OCT being located in the gastrointestinal tract, we hypothesized that the efficacy of OCT could be increased by specifically distributing OCT in the stomach rather than having it enter the systemic circulation. Then, the pharmacokinetics and pharmacodynamics of OCT were systematically studied to investigate the feasibility of developing an oral dosage form of OCT. The pharmacokinetic analysis indicated that OCT could be specifically enriched in the gastrointestinal tract rather than depend on the blood flow or perfusion rate of the organs for distribution. Additionally, SSTR2 was found to significantly affect the pharmacokinetic characteristics of OCT. In pharmacodynamic studies, OCT was confirmed to play a significant protective role in GMI via gavage administration. The pharmacological effectiveness after intragastric administration was comparable to that of subcutaneous injection (sc), and the high gastrointestinal tract expression of SSTR2 formed the basis of the efficacy of OCT on GMI.

The influence of SSTR2 on the pharmacokinetics and pharmacodynamics of OCT suggested that an oral formulation of OCT may also be applicable for other clinical indications, including neuroendocrine neoplasms and pituitary adenoma, due to the overexpression of SSTR2 in these tumor cells.

\section{Materials and methods}

\section{Chemicals and standards}

OCT acetate was purchased from Shanghai Guang Rui Biotechnology Co, Ltd (Shanghai, China). Oxidized-OCT (internal standard, IS) was synthesized by Shanghai Biotech Bioscience \& Technology Co, Ltd (Shanghai, China). CYN-154806 (antagonist of SSTR2) and BIM23056 (antagonist of SSTR5) were purchased from Abcam Inc (Cambridge, MA, USA). The Caco-2 cell line was purchased from American Type Culture Collection (Manassas, VA, USA). HCT116 and GES-1 cell lines were purchased from Shanghai AI Biotechnology Co, Ltd (Shanghai, China). Kits for the measurement of superoxide dismutase (SOD), glutathione (GSH), myeloperoxidase (MPO) and malondialdehyde (MDA) were purchased from JianCheng Bioengineering Institute (Nanjing, China). HPLC-grade acetonitrile and methanol were purchased from Merck Chemicals Co (Darmstadt, Germany). Ultra-pure grade water was pre- pared by a Milli-Q system (Millipore Corporation, Billerica, MA, USA). Other chemicals and solvents were of analytical grade.

\section{Animals}

Male healthy Sprague-Dawley rats (aged 7-8 weeks, weighing 180-220 g) and BALB/c mice (aged 3 weeks, weighing 13-15 g) were purchased from the Laboratory Animal Center of Peking University Health Science Center (Beijing, China) and acclimatized to the laboratory conditions (12:12 h lightdark cycle, temperature of $25^{\circ} \mathrm{C}$, and humidity of $55 \%$ ) for $5 \mathrm{~d}$ before experiments. The rats and mice were fed with standard laboratory food and water and then fasted overnight with free access to water prior to the dosing day. Experimental protocols were performed strictly in accordance with animal care and animal welfare laws and guidelines and approved by the China Pharmaceutical University Animal Care and Use Committee.

\section{Quantitative analysis of OCT in biological samples}

The analytical method for OCT was developed and validated in our previous study ${ }^{[18]}$. In the sample processing process, the specific operating steps were as follows: (i) The dosed and control rat tissues were removed $(\sim 50 \mathrm{mg})$ and homogenized in $1 \mathrm{~mL}$ of water $(\sim 50 \mathrm{mg} / \mathrm{mL})$. (ii) A total of $50 \mu \mathrm{L}$ of biological matrix (rat plasma/tissue homogenate) and $10 \mu \mathrm{L}$ of IS (oxidized-OCT) solutions were added to $1.5 \mathrm{~mL}$ Eppendorf tubes, and $200 \mu \mathrm{L}$ of acetonitrile was added to precipitate proteins. (iii) After mixing on a vortex mixer for $30 \mathrm{~s}$ and centrifugation at $15000 \times g$ for $10 \mathrm{~min}$, the supernatant $(200 \mu \mathrm{L})$ was transferred to clean Eppendorf tubes. (iv) Dichloromethane $(500 \mu \mathrm{L})$ was added to limit endogenous interferences from rat plasma, and $200 \mu \mathrm{L}$ of water was added to enhance the recovery. (v) After centrifugation at $40000 \times g$ for $5 \mathrm{~min}, 5 \mu \mathrm{L}$ of supernatant was injected into an LC/MS/MS system.

The LC separation was performed on a Shimadzu 30 AD ultra-fast liquid chromatography system, which included a binary pump, vacuum degasser, column oven and autosampler system. Chromatographic separation was achieved on a Sepax Bio-C18 column (150 mm×2.1 mm, $5 \mu \mathrm{m}, 300 \AA$ A using $0.1 \%$ formic acid (MPA) and methanol (MPB) as the mobile phase. The total flow rate was $0.2 \mathrm{~mL} / \mathrm{min}$, and the binary gradient elution was performed as follows: an isocratic elution of 5\% MPB for the first $1.0 \mathrm{~min}$, followed by a linear gradient elution of $5 \%-80 \% \mathrm{MPB}$ from 1 to $6 \mathrm{~min}$, holding the composition at $80 \% \mathrm{MPB}$ for the next $2 \mathrm{~min}$, followed by column equilibration to the initial conditions over $3 \mathrm{~min}$.

The MS analytical conditions were set as follows: a Shimadzu 8050 triple quadrupole mass spectrometer was operated in positive ion spray mode. Quantification was obtained using the multiple reactions monitoring (MRM) acquisition mode by monitoring the precursor ion to product ion transitions, $m / z 510.5 \rightarrow 120.1$ for OCT and $m / z 517.6 \rightarrow 120.1$ for oxidized-OCT (IS). The optimized ion spray voltage and source temperature were maintained at $4000 \mathrm{~V}$ and $300{ }^{\circ} \mathrm{C}$, respectively. LabSolutions LCMS Ver 5.6 software (Shimadzu, 
Japan) was used for instrument control and data processing.

\section{Pharmacokinetics of OCT in rats}

For the pharmacokinetic study, 24 rats were randomly divided into four groups, namely, $3(15,30$ and $60 \mathrm{mg} / \mathrm{kg})$ intragastric administration (ig) groups and 1 intravenous injection (iv) group. After drug administration, $100 \mu \mathrm{L}$ of heparinized blood was collected at 2, 5, 10, 20, 30, and $60 \mathrm{~min}$ and 1.5, 2, $3,5,7$ and $10 \mathrm{~h}$ from the ophthalmic veins and immediately centrifuged at $2000 \times g$ for $10 \mathrm{~min}$. Then, the concentrations of OCT in rat plasma were measured based on the validated LC-MS/MS method above.

Plasma concentration-time curves of OCT in rats were obtained by plotting the mean concentrations versus time. Pharmacokinetic parameters were calculated using the WinNonlin 6.3 program (Pharsight Corp, Mountain View, CA, USA). Two-compartmental and non-compartmental models were used to calculate the pharmacokinetic parameters for iv and ig group data, respectively. The following pharmacokinetic parameters were calculated: area under the plasma concentration-time curve from zero to the time of the last measurable concentration $\left(\mathrm{AUC}_{0-\mathrm{t}}\right)$, area under the plasma concentration-time curve from time zero to infinity ( $A \mathrm{UC}_{0-\infty}$ ), maximum observed plasma concentration $\left(C_{\max }\right)$, time to first occurrence of $C_{\max }\left(t_{\max }\right)$, half-life in elimination phase $\left(t_{1 / 2}\right)$ and clearance $(\mathrm{CL} / \mathrm{F})$.

\section{Imaging MS analysis of OCT in rat tissues based on iMScope}

The MS imaging method for OCT was developed and validated in our previous study ${ }^{[19]}$. IMScope, a hybrid IT-TOF mass spectrometer combining an optical microscope and matrix-assisted laser desorption/ionization source, was used to acquire the imaging MS data (Shimadzu Corporation, Kyoto, Japan). Tissue regions of interest (ROIs) were freely selected via a charge-coupled device (CCD) camera (magnification, $\times 1.25, \times 2.5, \times 5, \times 10, \times 20$, and $\times 40$; Olympus Corporation, Tokyo, Japan). All experiments in this study were conducted with the minimum irradiation diameter. The imaging area was then defined according to the maximum imaging points under a scan pitch of 5 to $20 \mu \mathrm{m}$. The parameters of ITTOF MS were set as follows: ion polarity, positive; mass range, 950-1200; sample voltage, $3.5 \mathrm{kV}$; detector voltage, $1.90 \mathrm{kV}$. Imaging MS Solution Version 1.12.26 software (Shimadzu Corporation, Kyoto, Japan) was used to control the instrument, and the data acquisition, visualization and quantification were also performed with the same software.

\section{Caco- 2 cell culture}

Caco-2 cells were routinely cultured in Dulbecco's modified Eagle's medium supplemented with $10 \%$ fetal bovine serum, $1 \%$ L-glutamine, $1 \mathrm{mmol} / \mathrm{L}$ sodium pyruvate, and $100 \mathrm{U} / \mathrm{mL}$ penicillin and streptomycin (Invitrogen, Carlsbad, CA, USA). Then, the cells were seeded at a density of $2 \times 10^{5}$ cells per well in 24-well microporous polycarbonate insert filter plates (0.4$\mu \mathrm{m}$ pore size) (Corning Life Sciences, MA, USA) and grown in a $\mathrm{CO}_{2}$ incubator at $37^{\circ} \mathrm{C}$ for $21 \mathrm{~d}$. Completeness of cell differ- entiation was validated by measuring the TEER of cell monolayers using a commercial apparatus (Millipore Co, Bedford, MA, USA) according to the manufacturer's instructions. The final values are expressed as $\Omega \times \mathrm{cm}^{2}$ on the basis of the following equation: TEER $=(R-R b) \times A$, where $R$ is the resistance of the filter insert with cells, $\mathrm{Rb}$ is the resistance of the filter alone and $\mathrm{A}$ is the growth area of the filter.

\section{MDCK-wild and MDR1-MDCK cell culture}

The Madin-Darby canine kidney cell line type II transfected with the human MDR1 gene (MDCK-MDR1) is a classical model for the transport studies to evaluate whether drug candidates are substrates of P-gp ${ }^{[20]}$. MDCK-wild and MDCKMDR1 cells were grown in Dulbecco's modified Eagle's medium with supplements at $37{ }^{\circ} \mathrm{C}, 5 \% \mathrm{CO}_{2}$, and $95 \%$ humidity and then seeded at a density of $12 \times 10^{6}$ cells per $150-\mathrm{cm}^{2}$ flask. To ensure a constant expression level of transport protein, MDR1-MDCK cells were grown in the presence of $640 \mathrm{nmol} / \mathrm{L}$ vincristine. Cells were grown as a monolayer on polycarbonate membrane filters (Transwell; Costar Corporation, Cambridge, MA, USA) as previously described ${ }^{[20]}$.

\section{Caco-2 cellular uptake of OCT}

For all cellular uptake studies, confluent monolayers of Caco-2 cells were grown in 24-well plastic plates. Caco-2 cells were pre-incubated at $37^{\circ} \mathrm{C}$ in modified Hank's balanced salt solution (HBSS; $137 \mathrm{mmol} / \mathrm{L} \mathrm{NaCl}, 5.4 \mathrm{mmol} / \mathrm{L} \mathrm{KCl}, 1.3 \mathrm{mmol} / \mathrm{L}$ $\mathrm{CaCl}_{2}, 0.8 \mathrm{mmol} / \mathrm{L} \mathrm{MgCl}_{2}, 0.4 \mathrm{mmol} / \mathrm{L} \mathrm{KH}_{2} \mathrm{PO} 4,0.3 \mathrm{mmol} / \mathrm{L}$ $\mathrm{NaH}_{2} \mathrm{PO} 4$, and $10 \mathrm{mmol} / \mathrm{L}$ HEPES/Tris, $\mathrm{pH}$ 7.4) for $1 \mathrm{~h}$ prior to the uptake experiments. For time-dependent uptake studies, $20 \mu \mathrm{g} / \mathrm{mL}$ OCT was incubated with Caco-2 cells for 10 , 20, 40, 60, 120, 180 and $240 \mathrm{~min}$. For concentration-dependent uptake studies, various concentrations $(2,5,20$ and 100 $\mu \mathrm{g} / \mathrm{mL}$ ) of OCT were incubated with Caco- 2 cells for $120 \mathrm{~min}$, and $200 \mu \mathrm{L}$ of cold acetonitrile was used to terminate the reaction.

\section{Transport study of OCT in cultured Caco-2, MDCK-wild and MDR1- MDCK cells}

For transcellular permeation experiments, Caco-2, MDCKwild and MDR1-MDCK cells were grown in 24-well Millicell cell culture inserts (Millipore, Bedford, MA, USA). Each well consisted of apical (top) and basal (bottom) chambers, which were separated by a collagen-coated polytetrafluoroethylene membrane with a pore size of $0.4 \mu \mathrm{m}$ and a filter area of 0.6 $\mathrm{cm}^{2}$. The Caco-2, MDCK-wild and MDR1-MDCK cells were washed twice with warm HBSS prior to transport experiments. HBSS containing digoxin $(5 \mu \mathrm{mol} / \mathrm{L}$, positive control $)$ and OCT $(20.0$ and $100.0 \mu \mathrm{g} / \mathrm{mL}$ ) or blank HBSS (control) was then loaded into either the apical or basolateral side to evaluate the transport in absorptive and secretory directions. The apparent permeability $\left(P_{\text {app }}, \mathrm{cm} / \mathrm{s}\right)$ in each direction $(\mathrm{A} \rightarrow \mathrm{B}$ and $\mathrm{B} \rightarrow \mathrm{A})$ was calculated as follows, where $A$ is the surface area of the membrane inserts $\left(0.6 \mathrm{~cm}^{2}\right), C_{0}$ is the initial concentration of the compound applied in the donor compartment, and $\Delta Q$ is the amount (micromoles) of compound transported over time 
$\Delta t(2 \mathrm{~h}=7200 \mathrm{~s})^{[21]}: P_{\text {app }}=\left(1 / \mathrm{A}^{*} \mathrm{C}_{0}\right)^{*}(\Delta \mathrm{Q} / \Delta t)$. The efflux ratio (ER) was a dimensionless number calculated as the ratio of the apparent permeability in the $\mathrm{B} \rightarrow \mathrm{A}$ direction divided by the apparent permeability in the $\mathrm{A} \rightarrow \mathrm{B}$ direction. $E R=P_{\text {app(BL-AP) }} /$ $P_{\text {app(AP-BL). }}$

\section{PCR analysis of SSTR, Gastrin and SST expression levels}

Real-time PCR analysis was performed on an ABI PRISM 7900 sequence detector (Applied Biosystems, San Diego, CA, USA) in 96-well plates. Total RNA of cells (HCT116, Caco-2 and GES-1) and mouse gastric homogenates was extracted using an Exiqon kit (Takara, Kyoto, Japan) and reverse-transcribed to cDNA using a PrimeScript RT Reagent Kit (Takara, Kyoto, Japan). Expression levels of the human SSTRs (SSTR2, SSTR3 and SSTR5); mouse SSTR2, SSTR3 and SSTR5; mouse gastrin; and mouse somatostatin were measured by real-time PCR with specific primers according to the MIQE-guidelines ${ }^{[22]}$ (Supplementary Table S1). Each experiment was performed in triplicate with at least 6 independent samples. The data were analyzed using SDS 2.2 Software (Applied Biosystems). $18 \mathrm{~S}$ RNA served as an endogenous control to normalize the amount of cDNA added to each reaction $(\Delta \mathrm{Ct})$, and the mean $\Delta \mathrm{Ct}$ of control samples was used to calculate the $\Delta \Delta \mathrm{Ct}$ values. Data sets were evaluated using T-tests or one-way analysis of variance (ANOVA) followed by Tukey's post-hoc tests and expressed as the mean $\pm \mathrm{SD}$. Statistically significant differences were determined at $P<0.05$.

\section{Immunohistochemistry}

Rat stomachs were cut into slices ( $15 \mu \mathrm{m}$ thick) after paraffin embedding. Then, the endogenous peroxidase of the slices was blocked with freshly prepared $\mathrm{H}_{2} \mathrm{O}_{2}(0.3 \%)$. After washing with phosphate-buffered solution (PBS, $\mathrm{pH}$ 7.4) three times, the stomach slices were blocked with $10 \%$ fetal calf serum (FCS) for $30 \mathrm{~min}$. Polyclonal rabbit anti-mouse SSTR2, SSTR3 and SSTR5 primary antibodies (Alomone Lab, Jerusalem, Israel) were used at dilutions of 1:500, 1:250 and 1:250, respectively. Then, the stomach sections were incubated with the primary antibodies overnight at $4{ }^{\circ} \mathrm{C}$. After rinsing the slides three times using PBS, the sections were incubated with a secondary anti-goat antibody (Abcam, Cambridge, MA, USA) diluted at 1:200 in 10\% FCS for $30 \mathrm{~min}$ at room temperature, followed by washing three times for 5 min each. After incubation with avidin-biotin-peroxidase complex for $30 \mathrm{~min}$ at room temperature, the sections washed three times using PBS. The nuclei of retinal cells were stained with hematoxylin and eosin (H\&E). Slides were examined using a fluorescence microscope (Axiophot, Carl Zeiss, Germany) with the appropriate filters.

The effect of SSTRs on the uptake of OCT in HCT116, Caco-2 and GES-1 cells

For the uptake study, the cells were divided into 3 groups (OCT, OCT+SSTR2 antagonist and OCT+SSTR5 antagonist). In the control group, HCT116, Caco-2 and GES-1 cells were incubated with $20 \mu \mathrm{g} / \mathrm{mL}$ OCT for $90 \mathrm{~min}$ after incubating with $1 \mathrm{~mL}$ of blank HBSS for $30 \mathrm{~min}$. In the OCT+SSTR2 antagonist group, HCT116, Caco-2 and GES-1 cells were incubated with $20 \mu \mathrm{g} / \mathrm{mL}$ OCT for $90 \mathrm{~min}$ after preincubation with $20 \mu \mathrm{mol} / \mathrm{L}$ CYN-154806 (antagonist of SSTR2, prepared in $1 \mathrm{~mL}$ of HBSS) for $30 \mathrm{~min}$. In the OCT+SSTR3 antagonist group, HCT116, Caco-2 and GES-1 cells were incubated with $20 \mu \mathrm{g} / \mathrm{mL}$ OCT for $90 \mathrm{~min}$ after preincubation with $20 \mu \mathrm{mol} / \mathrm{L}$ BIM23056 (antagonist of SSTR5, dissolved in $1 \mathrm{~mL}$ of HBSS) for $30 \mathrm{~min}$. Then, HBSS solution $\left(4^{\circ} \mathrm{C}\right)$ was used to rinse the cells 3 times. After ultrasonic crushing of the cells, the concentrations of OCT in the cells were determined based on LC-MS/ MS, and the protein concentrations of the cells were measured using Coomassie Brilliant Blue stain.

\section{The effect of SSTRs on the tissue distribution of OCT in the rat gastrointestinal tract}

Mice $(n=10)$ were randomly divided into 2 groups (OCT, OCT+SSTR2 antagonist). In the OCT group, mice $(n=5)$ were administered $0.5 \mathrm{~mL}$ of saline via caudal vein injection. Ten minutes later, the mice were iv administered $1 \mathrm{mg} / \mathrm{kg}$ OCT. In the OCT+SSTR2 antagonist group, mice $(n=5)$ were administered $5 \mathrm{mg} / \mathrm{kg}$ CYN-154806 (antagonist of SSTR2, dissolved in $0.5 \mathrm{~mL}$ of saline) via caudal vein injection. Ten minutes later, the mice were iv administered OCT at a dose of $1 \mathrm{mg} / \mathrm{kg}$. All the mice were executed by exsanguination from the arteria cruralis $30 \mathrm{~min}$ after administration of $\mathrm{OCT}$, and the concentrations of OCT in the stomach, duodenum, jejunum, ileum and colon were measured by LC-MS/MS.

\section{Preparation of simulated gastric fluid and simulated intestinal} fluid

Simulated gastric fluid (SGF, $\mathrm{pH}$ 1.5) was prepared with a buffer mixture composed of $0.2 \mathrm{~mol} / \mathrm{L} \mathrm{HCl}$ and $0.2 \mathrm{~mol} / \mathrm{L} \mathrm{KCl}$, to which $10 \mathrm{U} / \mathrm{mL}$ pepsin was added. Simulated intestinal fluid (SIF, pH 6.8) was prepared by adding $\mathrm{KH}_{2} \mathrm{PO}_{4}(6.8 \mathrm{~g}$ ) to 500 $\mathrm{mL}$ of $\mathrm{H}_{2} \mathrm{O}$, and the $\mathrm{pH}$ was adjusted by $0.4 \% \mathrm{NaOH}(w / w)$. Then, $5 \mathrm{~g}$ of trypsin was added to this solution.

\section{Protective effect of OCT on water-immersion and restraint stress (WIRS) gastric ulcer mice}

Group 1: Control group $(n=6)$. No stress or treatment was applied to the mice in this group.

Group 2: Model group $(n=6)$. The mice were ig administered saline $(5 \mathrm{~mL} / \mathrm{kg})$ before modeling. Then, the mice were restrained individually in $50 \mathrm{~mL}$ of Eppendorf tubes and immersed up to the depth of the xiphoid process in an $18 \pm 1^{\circ} \mathrm{C}$ water bath. Three hours later, the mice were ig administered saline $(5 \mathrm{~mL} / \mathrm{kg})$ again and immersed in the $18 \pm 1^{\circ} \mathrm{C}$ water bath for another $3 \mathrm{~h}$ to induce WIRS ${ }^{[23]}$. Animals were then sacrificed by anesthesia, and the experiment was terminated after sampling.

Group 3: WIRS+ig OCT group $(n=30)$. Mice were ig administered OCT $(1.0,10.0,100 \mu \mathrm{g} / \mathrm{kg}, 1.0$ or $10 \mathrm{mg} / \mathrm{kg})$ before modeling. Then, the mice were restrained individually in 50-mL Eppendorf tubes and immersed up to the depth of the xiphoid process in an $18 \pm 1{ }^{\circ} \mathrm{C}$ water bath. Three hours later, 
the mice were ig administered OCT again and immersed in the $18 \pm 1^{\circ} \mathrm{C}$ water bath for another $3 \mathrm{~h}$.

Group 4: WIRS+sc OCT group $(n=6)$. Mice were sc administered OCT $(0.1 \mathrm{mg} / \mathrm{kg})$ before modeling. Then, the mice were restrained individually in 50-mL Eppendorf tubes and immersed up to the depth of the xiphoid process in an $18 \pm 1^{\circ} \mathrm{C}$ water bath. Three hours later, the mice were sc administered OCT $(0.1 \mathrm{mg} / \mathrm{kg})$ again and immersed in the $18 \pm 1{ }^{\circ} \mathrm{C}$ water bath for another $3 \mathrm{~h}$.

Protective effect of OCT on alcohol-induced gastric mucosal injury (AGMI) rats

Group 1: Control group $(n=6)$. No alcohol or treatment was applied to the rats in this group.

Group 2: AGMI model group $(n=6)$. The rats were ig administered saline $(5 \mathrm{~mL} / \mathrm{kg})$ before modeling. Then, the rats were ig administered alcohol (100\%) at a dose of $5 \mathrm{~mL} / \mathrm{kg} 30 \mathrm{~min}$ later.

Group 3: AGMI+ig OCT group $(n=30)$. The rats were ig administered OCT $(0.1,1.0,10.0 \mu \mathrm{g} / \mathrm{kg}, 0.1$ or $1.0 \mathrm{mg} / \mathrm{kg})$ before modeling. Then, the rats were ig administered alcohol $(100 \%)$ at a dose of $5 \mathrm{~mL} / \mathrm{kg} 30 \mathrm{~min}$ later.

Group 4: AGMI+sc OCT group $(n=6)$. The rats were sc administered OCT $(0.1 \mathrm{mg} / \mathrm{kg})$ before modeling. Then, the rats were ig administered alcohol (100\%) at a dose of $5 \mathrm{~mL} / \mathrm{kg}$ 30 min later.

\section{Determination of the ulcer index}

Mucosal lesions were enumerated as previously reported ${ }^{[24]}$. In brief, 1 point was assigned for small round hemorrhagic corrosions; 2 points were assigned when the length of the hemorrhagic corrosions was $<1 \mathrm{~mm} ; 3$ points were assigned when the length was $1-2 \mathrm{~mm} ; 4$ points were assigned when the length was $2-3 \mathrm{~mm}$; and 5 points were assigned when the length was $>4 \mathrm{~mm}$. This score was added and doubled when the width of the corrosions was $>1 \mathrm{~mm}$.

\section{Determination of SOD, GSH and MPO in mouse stomach}

Mouse stomach samples were homogenized in $0.9 \%$ saline solution and centrifuged for $10 \mathrm{~min}$ at $2500 \times g$. The supernatant was used to measure the SOD, GSH and MPO levels using corresponding ELISA kits according to the manufacturer's instructions. The activities of MDA, SOD and MPO were determined spectrophotometrically at 532, 550 and $460 \mathrm{~nm}$ and expressed as U/mg of protein. Each measurement was performed in triplicate.

\section{Preparation of pyloric ligation-induced ulcer (PLIU) model mice}

A total of 36 mice were fasted for $24 \mathrm{~h}$ before surgery with free access to water. After $1 \mathrm{~h}$ of drug treatment (ig administration at a dosage of $10 \mathrm{mg} / \mathrm{kg}$ or sc administration at a dosage of 0.1 $\mathrm{mg} / \mathrm{kg}$ ), all the mice were anesthetized with $50 \mathrm{mg} / \mathrm{kg}$ pentobarbital. The mouse abdomen was opened below the xiphoid process. The pyloric portion of the mouse stomach was lifted slightly out and ligated by a surgical tie. After closing the abdominal wall with interrupted sutures, the mice were sac- rificed by an overdose of anesthetic ether. Six hours later, the abdomen was opened. The cardiac end of the stomach was removed, and the contents in the stomach were drained into glass tubes. The volume of the gastric juice was measured after centrifugation at $2000 \times g$ for $10 \mathrm{~min}$. The supernatant was used to determine the $\mathrm{pH}$ and the total acidity of the gastric juices.

\section{Determination of total acidity of gastric juices}

An aliquot of $0.1 \mathrm{~mL}$ of gastric juice was diluted with $0.9 \mathrm{~mL}$ of distilled water. Two drops of phenolphthalein indicator were added and titrated with $0.01 \mathrm{~mol} / \mathrm{L} \mathrm{NaOH}$ until a permanent pink color was observed. The volume of consumed $\mathrm{NaOH}$ was recorded at the end of the titration, and the total acidity was calculated by the following formula: Acidity $(\mathrm{mEq} / \mathrm{L})=$ $\mathrm{V}_{\mathrm{NaOH}} \times \mathrm{N} \times 100 / 0.1$.

\section{Results}

\section{Pharmacokinetics of OCT in rats}

The mean plasma concentration-time profiles of OCT in rats measured by LC-MS/MS are shown in Figure 1A. After iv administration of OCT to rats at a single dose of $0.1 \mathrm{mg} / \mathrm{kg}$, the geometric mean half-life $\left(t_{1 / 2 \beta}\right)$ was $0.34 \pm 0.06 \mathrm{~h}$, and the
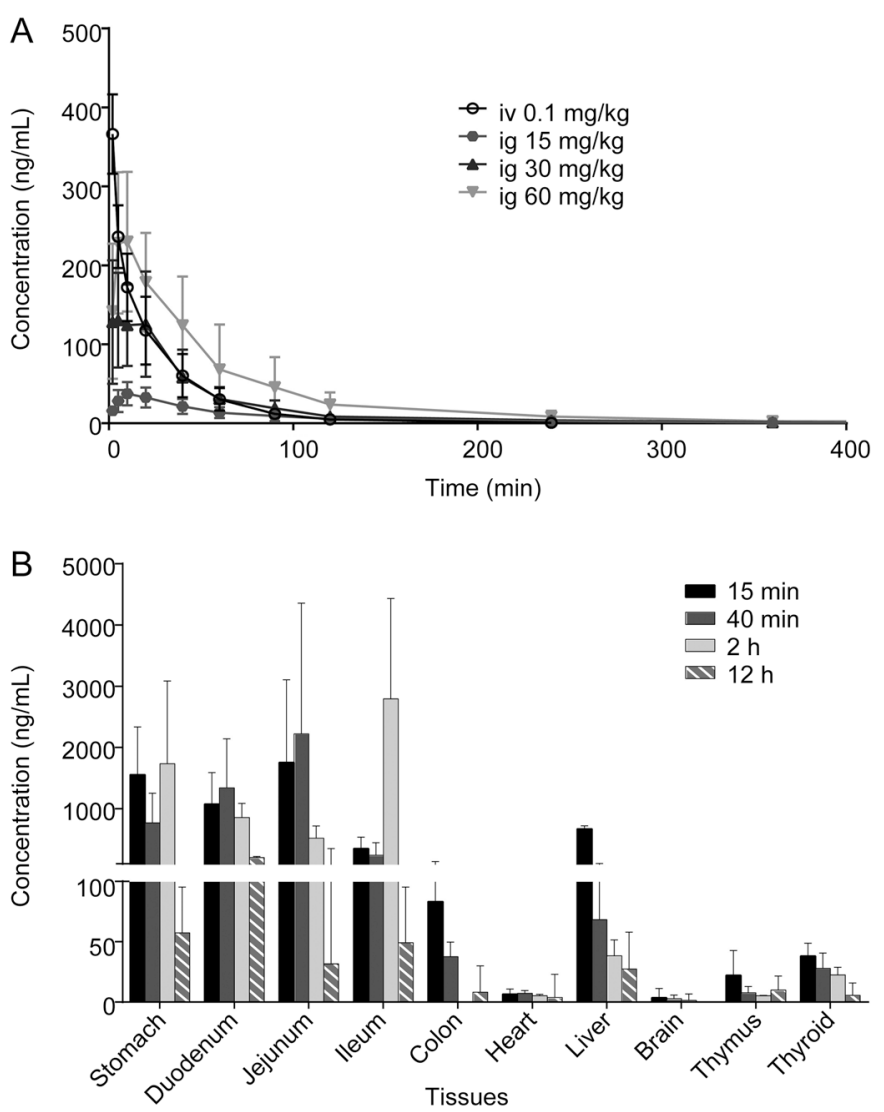

Figure 1. The concentrations of OCT in rat plasma and tissues. (A) The mean plasma concentration-time profiles of OCT in rats, as measured by LC-MS/MS; (B) The concentrations of OCT in rat tissues after oral treatment of OCT at a dose of $30 \mathrm{mg} / \mathrm{kg}$. 
$\mathrm{AUC}_{0-\infty}$ was $130.0 \pm 37.4 \mathrm{ng} \cdot \mathrm{h} / \mathrm{mL}$ (Supplementary Table S2). The mean $C_{\max }$ of OCT after ig administration at doses of 15, 30 and $60 \mathrm{mg} / \mathrm{kg}$ were $43.4 \pm 10.9,176.7 \pm 63.6$ and $257.3 \pm 88.6$ $\mathrm{ng} / \mathrm{mL}$, respectively. The mean $t_{1 / 2}$ of OCT was $1.85 \pm 0.44$, $1.73 \pm 0.48$ and $1.58 \pm 0.47 \mathrm{~h}$, which indicates that the elimination rate of ig administration was significantly longer than that of iv administration. The mean $\mathrm{AUC}_{0-\infty}$ after ig administration of 15,30 and $60 \mathrm{mg} / \mathrm{kg}$ OCT was $68.5 \pm 26.3,189.4 \pm 59.7$ and $342.5 \pm 164.7 \mathrm{ng} \cdot \mathrm{h} / \mathrm{mL}$, respectively. These results suggest that OCT could enter the systemic circulation after ig administration; however, the bioavailability in rats was extremely low $(<0.5 \%)$.

\section{The specific distribution of OCT in rat tissues}

After oral treatment with OCT at a dose of $30 \mathrm{mg} / \mathrm{kg}$, the concentrations of OCT in rat tissues were measured by LC-MS/ MS, and the results are shown in Figure 1B. Clearly, OCT was enriched in the gastrointestinal tract after ig administration, and the concentrations in the stomach, duodenum, jejunum, and ileum were much higher than those in the heart, liver, brain, thymus and thyroid. These results implied that OCT could be specifically enriched in the gastrointestinal tract rather than distribute in a manner dependent on the blood flow or perfusion rate of organs after oral administration.

To further elucidate tissue-specific distribution characteristics, we investigated whether OCT could specifically distribute to the gastric mucosa after intravenous iv administration. In this process, rat stomachs were collected at 10, 20, 40, 60 and $120 \mathrm{~min}$ after iv administration of a single dose of OCT (0.1 $\mathrm{mg} / \mathrm{kg}$ ), and $10-\mu \mathrm{m}$-thick stomach sections were sliced at -20 ${ }^{\circ} \mathrm{C}$ with a cryomicrotome (Leica CM1950, Nussloch, Germany). Then, the tissue distribution of OCT in the stomach sections was measured with a Shimadzu iMScope at a lateral resolution at $50 \mu \mathrm{m}$ and a small pixel size at $5 \mu \mathrm{m}$. The stomach mucosa and musculature could be clearly distinguished by the CCD camera at 20× magnification (Figure 2). Clearly, OCT could also distribute to the stomach after iv administration. Furthermore, the exposure level of OCT in the gastric mucosal layer was markedly higher than that in the musculature from 10 to 120 min post-administration, which fully illustrated that OCT could specifically distribute to gastric mucosa.

\section{The effects of SSTRs on the pharmacokinetics of OCT}

SSTRs are expressed in both normal and neoplastic tissues,
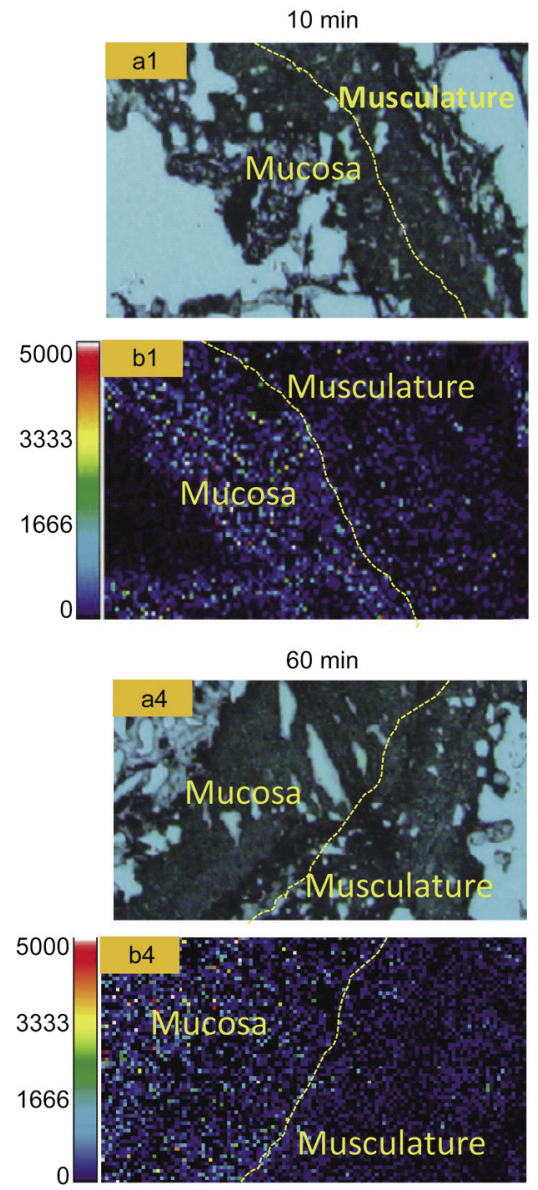

$20 \min$
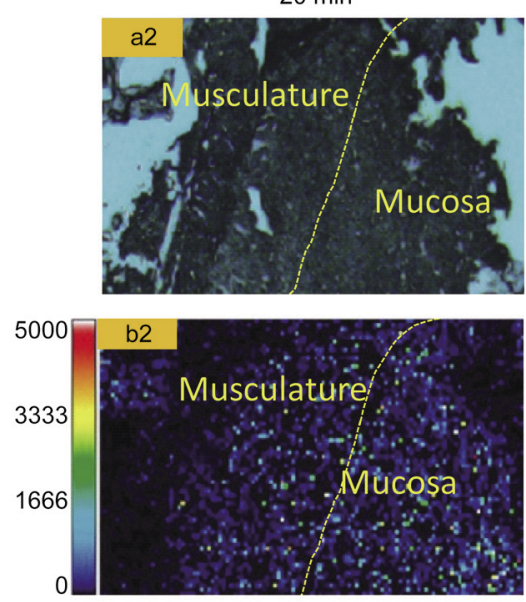

$120 \mathrm{~min}$
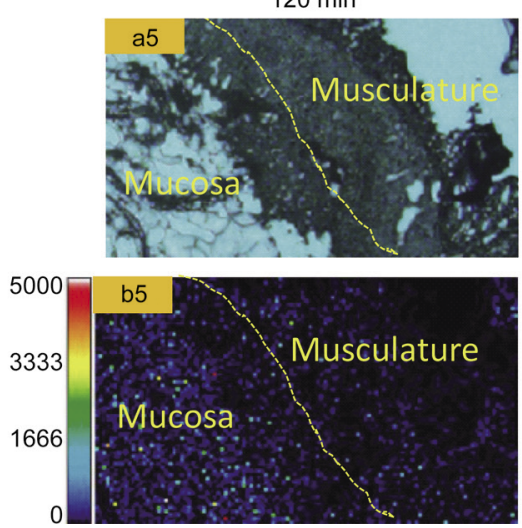

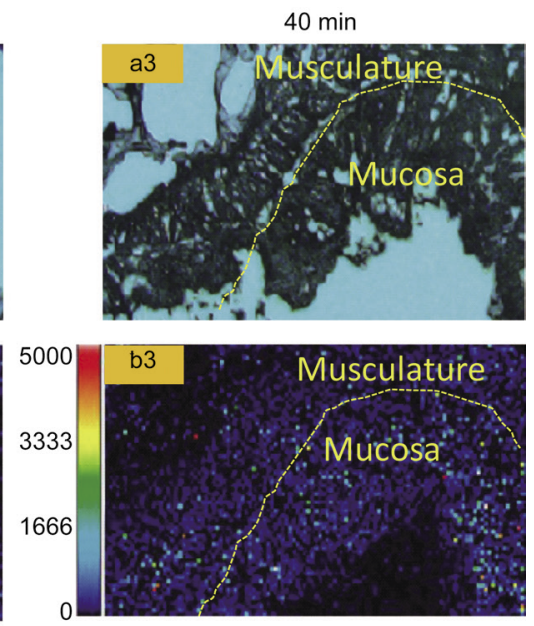

Figure 2. The spatial distribution and elimination of OCT in mouse stomachs after intravenous administration of OCT at a dose of $0.1 \mathrm{mg} / \mathrm{kg}$. The spatial distribution of OCT at 10 min (a1, b1), 20 min (a2, b2), 40 min (a3, b3), 60 min (a4, b4) and 120 min (a5, b5) post-dose (a1 to a5: magnified view of the mouse stomach; a1 to a5: MS imaging analysis of octreotide). 
yet the characteristic expression pattern of SSTR subtypes is tissue specific and subtype specific ${ }^{[9,25]}$. According to previous studies, the therapeutic effects of somatostatin analogs depend on the expression of specific somatostatin receptors on target cells, and the expression of SSTRs on cells and tissues forms the basis for the efficacy of somatostatin analogs ${ }^{[26,27]}$. The tissue-distribution characteristics of OCT suggested that the distribution process of OCT may be mediated by SSTRs. Herein, the effects of SSTRs on the pharmacokinetics of OCT were systematically investigated in vitro (HCT116, Caco-2 and GES-1 cells) and in vivo (stomach, duodenum, jejunum, ileum and colon). Initially, the expression levels of the main SSTRs (SSTR2, SSTR2 and SSTR5) in HCT116, Caco-2 and GES-1 cells were measured via RT-PCR (Figure 3A-3C). Clearly, the expression levels of SSTR2 and SSTR5 were significantly higher than those of SSTR3 in HCT116, Caco-2 and GES-1 cells, and the mRNA levels of SSTR2 were similar to those of SSTR5. Next, antagonists of SSTRs were used to investigate the influence of SSTRs on the uptake of OCT in cells. As shown in Figure 3D, an antagonist of SSTR2 (CYN-154806) could significantly reduce the uptake of OCT in HCT116, Caco-2 and GES-1 cells. Similarly, an antagonist of SSTR5 (BIM23056) could also dramatically decrease the uptake of OCT in HCT116, Caco-2 and GES-1 cells. Then, the expression of SSTR2, SSTR2 and SSTR5 in the rat gastrointestinal tract was measured based on RT-PCR and fluorescence immunoassay. The relative expression of SSTR2, SSTR3 and SSTR5 in the rat stomach, duodenum, jejunum, ileum and colon is illustrated in Figure 4A. The expression of SSTR2 was much higher than that of SSTR3 and SSTR5 in the stomach, duodenum and jejunum. In the rat ileum and colon, the expression levels of SSTR2 and SSTR3 were much higher than those of SSTR5, and the mRNA levels of SSTR2 were similar to those of SSTR3. The expression of SSTR2, SSTR3 and SSTR5 in the rat stomach was also assessed by fluorescence immunoassay. Clearly, the expression of SSTR2 was significantly higher than that of SSTR3 and SSTR5 in the rat stomach, and the expression of SSTR2 in the gastric mucosal layer was much higher than that on the musculature side (Figure 4B-4D). Finally, an antagonist of SSTR2 (CYN-154806) was used to investigate the influence of SSTR2 on the distribution of OCT in rats due to the high expression of SSTR2 in the rat stomach, duodenum and jejunum. As shown in Figure $4 \mathrm{E}$, the concentrations of OCT in the rat stomach were significantly decreased by CYN154806 treatment $(P<0.05)$, and the concentrations of OCT in the rat duodenum and jejunum were also decreased by CYN-154806 to a lesser extent. In the rat ileum and colon, the concentrations of OCT were not affected by SSTR2 antagonist treatment. Thus, the regulatory strength of SSTRs on octreotide pharmacokinetics was consistent with SSTR expression
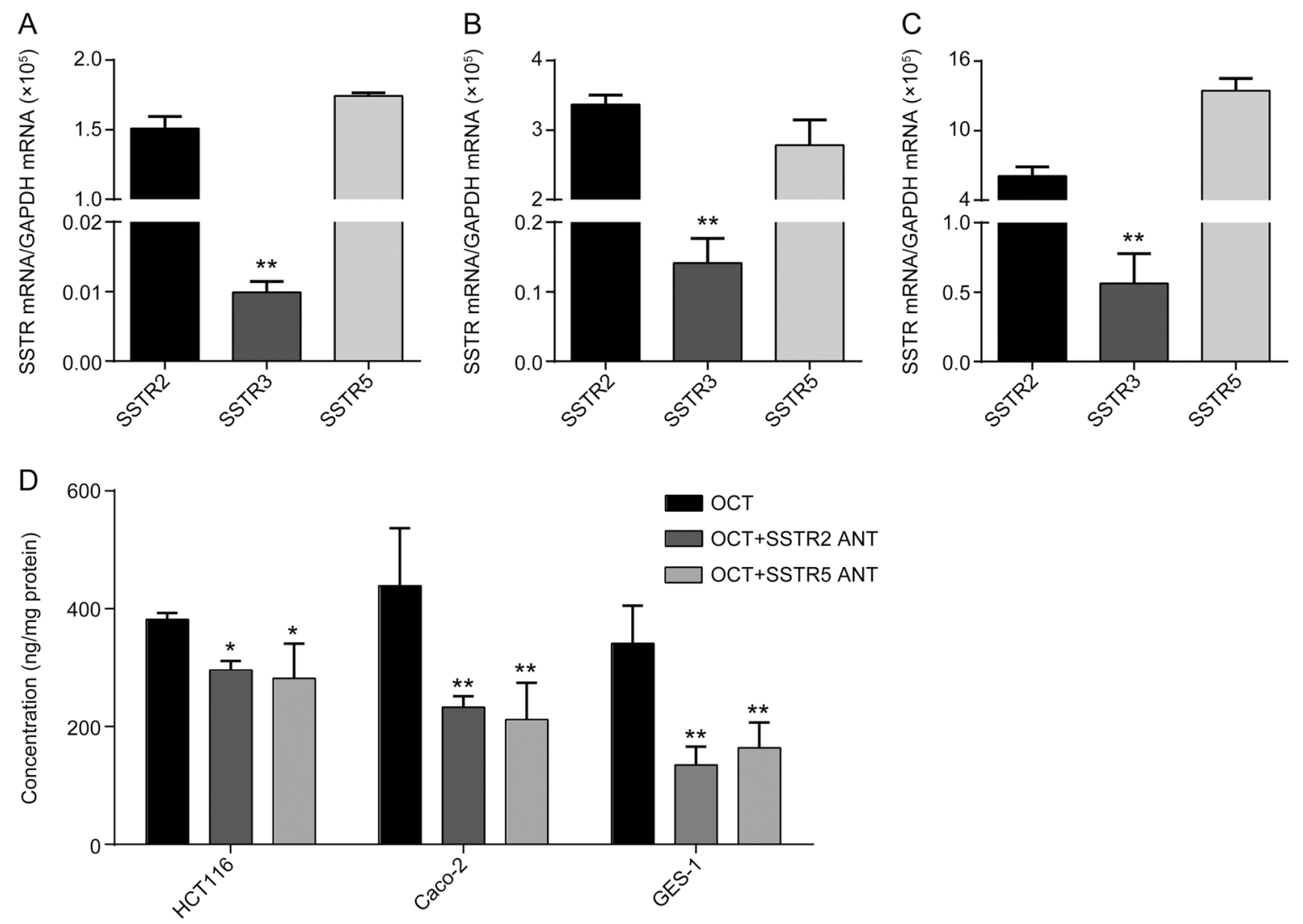

Figure 3. The expression levels of the main SSTRs in HCT116 (A), Caco-2 (B) GES-1 (C) cells, and the influence of SSTRs on the uptake of OCT in cells (D). ${ }^{*} P<0.05,{ }^{* *} P<0.01$. 

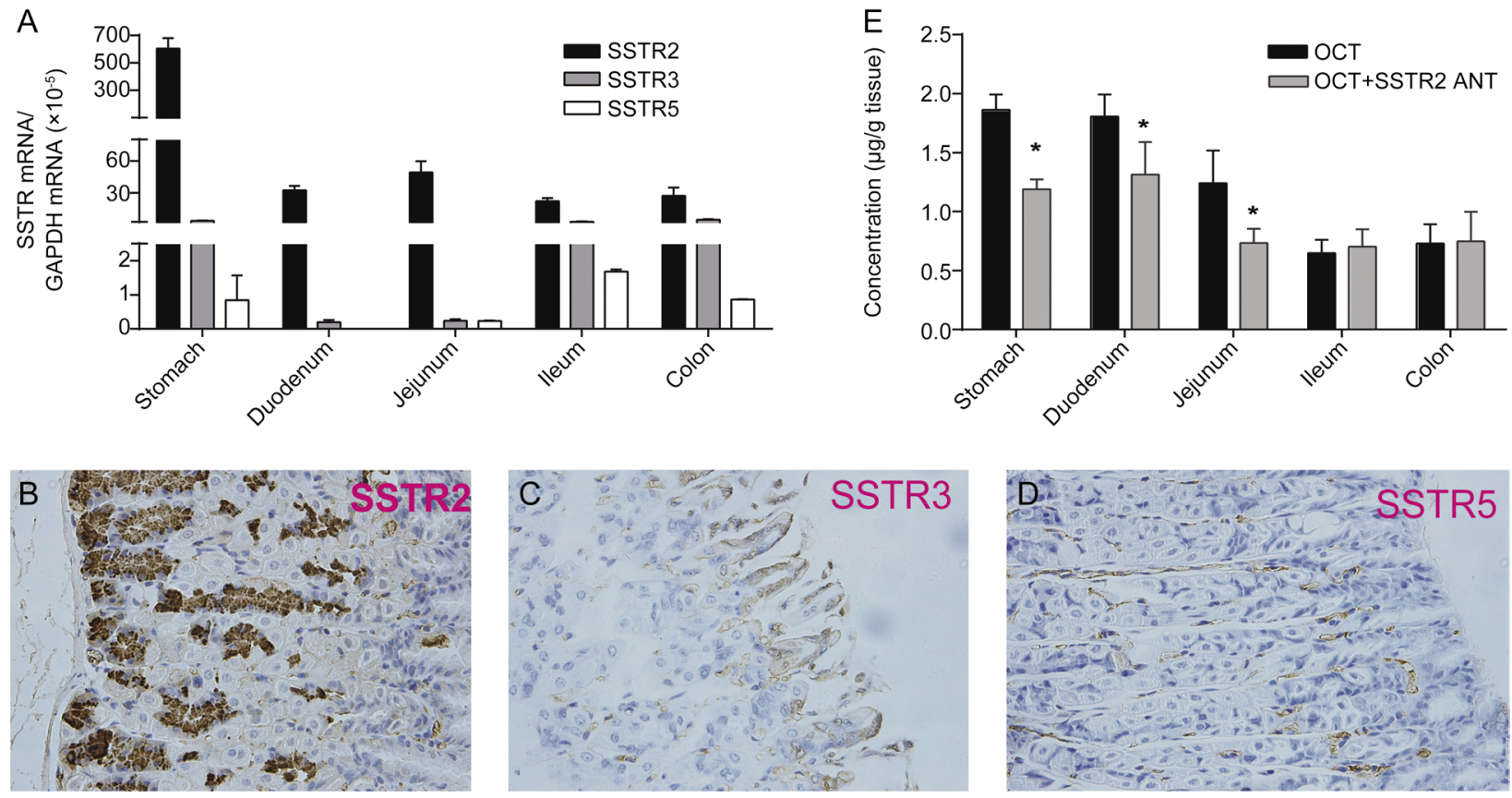

Figure 4. The expression levels of the main SSTRs in rat tissues, and the influence of SSTRs on the distribution of OCT in rats. (A) The relative expression levels of SSTR2, SSTR3 and SSTR5 in rat stomach, duodenum, jejunum, ileum and colon; (B) The expression of SSTR2 in rat stomach sections; (C) The expression of SSTR3 in rat stomach sections as measured by fluorescence immunoassay; (D) The expression of SSTR5 in rat stomach sections; (E) The effects of SSTR2 antagonists on the distribution of OCT. ${ }^{*} P<0.05$.

levels in the rat gastrointestinal tract.

\section{Protective effect of OCT on WIRS mice}

OCT-treated mice received a single ig administration of OCT $(1.0,10.0,100 \mu \mathrm{g} / \mathrm{kg}, 1.0$ or $10 \mathrm{mg} / \mathrm{kg}$ ) or sc administration of OCT $(0.1 \mathrm{mg} / \mathrm{kg})$ before modeling. After $3 \mathrm{~h}$ of WIRinduced stress, the mice were ig administered OCT $(1.0,10.0$, $100 \mu \mathrm{g} / \mathrm{kg}, 1.0$ or $10 \mathrm{mg} / \mathrm{kg}$ ) again and continued undergoing WIR-induced stress for another $3 \mathrm{~h}$. The murine stomachs were subsequently collected to assess gastric injury (Figure $5 \mathrm{~A}$ and $5 \mathrm{~B})$. Clearly, the surface of the gastric mucosa in the normal mice was smooth, and no damage was observed. In the model mice, there was accumulated blood in the stomach cavity, and many bloody scabs on the mucosa surface were observed. The lesion area was calculated as $3.62 \% \pm 2.60 \%$. In contrast, OCT could decrease the lesion area in a dose-dependent manner. When the dosage reached $1 \mathrm{mg} / \mathrm{kg}$, the lesion area of the OCT-treated mice was significantly lower than that of the model mice $(P<0.05)$. Moreover, the lesion area of the ig group mice at dosages of 1 and $10 \mathrm{mg} / \mathrm{kg}$ was comparable to that of the sc group mice.

MDA, SOD and MPO are important indicators of GMI ${ }^{[28]}$. In this process, the activity levels of MDA, SOD and MPO were determined, and the results are illustrated in Figure 5C to 5E. Significant elevation in MDA and MPO activity levels were observed in the model group in comparison to the control group. Both ig administration of $1.0 \mathrm{mg} / \mathrm{kg} \mathrm{OCT}$ and sc administration at a dosage of $0.1 \mathrm{mg} / \mathrm{kg}$ could efficiently attenuate the marked elevation in MDA and MPO caused by WIRS. Moreover, the activity of SOD was decreased in the WIRS-induced group compared with the control group, and oral treatment with OCT could enhance the activity of SOD in dose-dependent manner. Both ig administration of OCT at a dosage of $1.0 \mathrm{mg} / \mathrm{kg}$ and sc administration at a dosage of $0.1 \mathrm{mg} / \mathrm{kg}$ could significantly enhance the activity of SOD in murine stomachs. The activities of MDA, SOD and MPO in the ig group at a dosage of $1 \mathrm{mg} / \mathrm{kg}$ were comparable to those of the sc group.

\section{The influence of SSTRs on the protective effects of OCT in WIRS} mice

The above results demonstrated that SSTR2 could significantly affect the pharmacokinetics of OCT in vivo and in vitro. The influence of SSTRs on the protective effects of OCT was subsequently investigated in WIRS model mice. As shown in Figure $6 \mathrm{~A}$ and $6 \mathrm{~B}, \mathrm{OCT}$ could significantly decrease lesion areas by either ig administration at $1.0 \mathrm{mg} / \mathrm{kg}$ or sc administration at $0.1 \mathrm{mg} / \mathrm{kg}$, and the protective effects of OCT in gastric injury were markedly reduced when used in combination with an antagonist of SSTR2 (CYN-154806). Meanwhile, both ig and sc administration of OCT could down-regulate the MDA levels in WIRS model mice, and the activity of OCT was significantly reduced when used in combination with the SSTR2 antagonist (Figure 6C). Furthermore, the antagonist of SSTR2 could significantly attenuate the effect of OCT in elevating SOD levels in WIRS model mice (Figure 6D). 


\section{A}

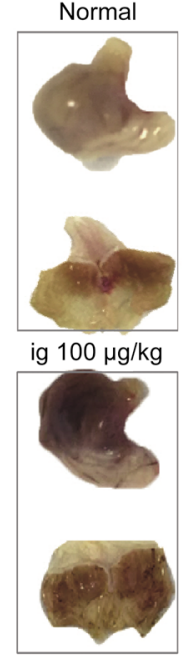

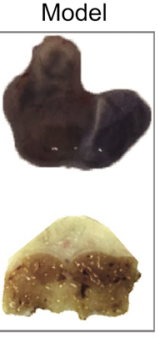

ig $1 \mathrm{mg} / \mathrm{kg}$

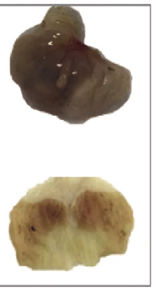

ig $1 \mu \mathrm{g} / \mathrm{kg}$

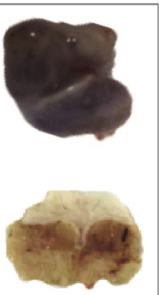

ig $10 \mathrm{mg} / \mathrm{kg}$

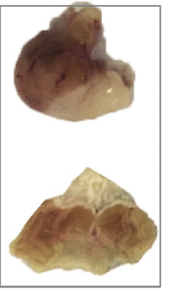

ig $10 \mu \mathrm{g} / \mathrm{kg}$

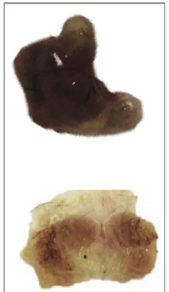

sc $0.1 \mathrm{mg} / \mathrm{kg}$

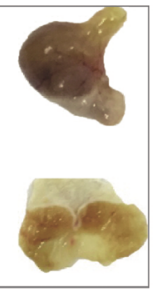

B

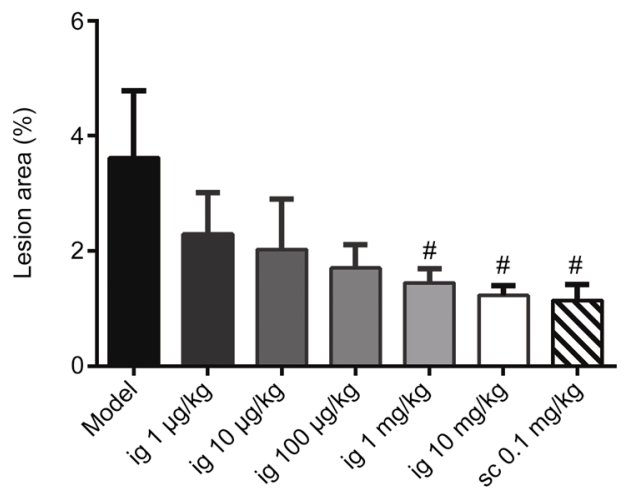

C

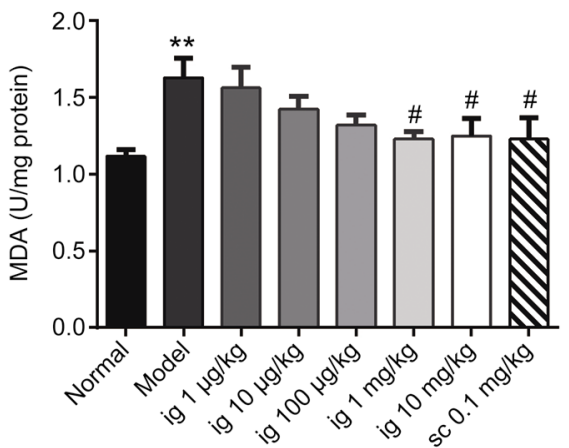

D

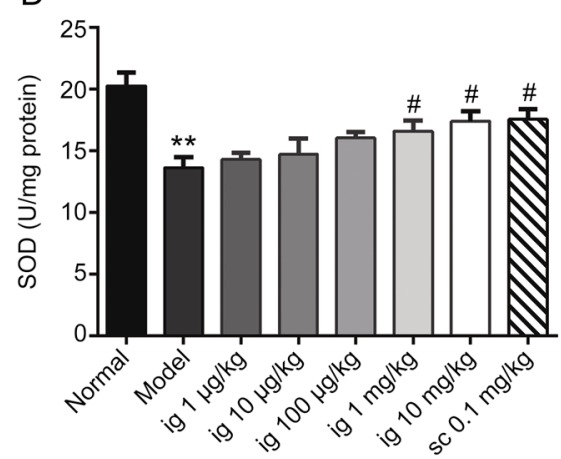

E

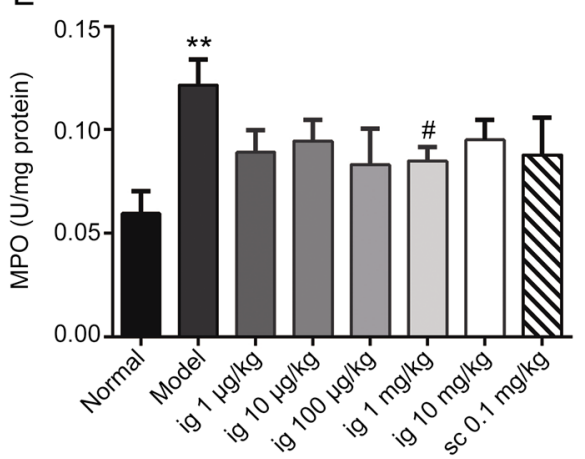

Figure 5. Protective effects of OCT on WIRS-mouse gastric ulcers after ig and sc administration. (A) Images of the rat stomachs of control, model and OCT-treated groups; (B) The lesion areas (\%) of rat mouse stomachs in model and OCT-treated groups; (C) The MDA levels in rat stomachs of control, model and OCT-treated groups; (D) The SOD levels in rat stomachs of control, model and OCT-treated groups; (E) The MPO levels in rat stomachs of control, model and OCT-treated groups. ${ }^{* *} P<0.01$ vs normal group. ${ }^{*} P<0.05$ vs model group.

\section{Protective mechanism of OCT in WIRS}

The effect of OCT on the expression of SST, gastrin, and SSTR2 was investigated to characterize the protective mechanism of OCT in WIRS. As shown in Figure 7A, the expression levels of SST in WIRS model mice were much higher than those in the control group, and neither ig nor sc administration of OCT could reverse the up-regulation of SST caused by WIRS. The expression of SSTR2 was not affected by WIRS and OCT (Figure 7B). Gastrin, a peptide hormone produced by gastric parietal cells, can stimulate digestion and secretion of gastric acid $^{[29]}$. As shown in Figure 7C, the expression level of gastrin in the WIRS model group was significantly higher than that in the control group, and both intragastric and injection administration of OCT could dramatically attenuate the elevation of gastrin caused by WIRS.

The regulation by OCT of gastrin led to the following hypothesis: OCT can reduce the secretion of gastric acid via down-regulating the gastrin level, subsequently playing a protective role in gastric injury. The PLIU model was utilized to investigate the influence of OCT on gastric acid secretion (Figure 7D). In this process, OCT treatment was found to signifi- cantly decrease lesion areas by either ig administration at 1.0 $\mathrm{mg} / \mathrm{kg}$ or sc administration at $0.1 \mathrm{mg} / \mathrm{kg}$, and the protective effects of OCT against gastric injury were markedly reduced when used in combination with CYN-154806 (Figure 7E). The expression level of gastrin in PLIU mice was significantly higher than that in normal mice, and both ig and sc administration of OCT could dramatically attenuate the elevation of gastrin caused by mechanical pyloric ligation. The use of an SSTR2 antagonist in combination with OCT led to a reduction in the regulation of gastrin by OCT (Figure 7F). Importantly, both intragastric and subcutaneous injection administration of OCT could dramatically attenuate the elevation in gastric acidity caused by mechanical pyloric ligation, and the trend in changes in gastric acid were consistent with that of gastrin. Moreover, the effect of OCT on gastric acid was markedly attenuated when used in combination with the antagonist of SSTR2 (Figure 7G).

\section{Discussion}

Generally, the clinical use of hydrophilic peptides has been limited to parenteral routes (including iv, sc, intramuscular 


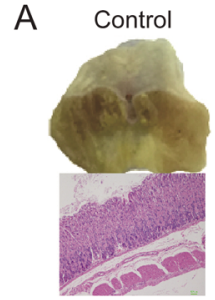

Sc OCT
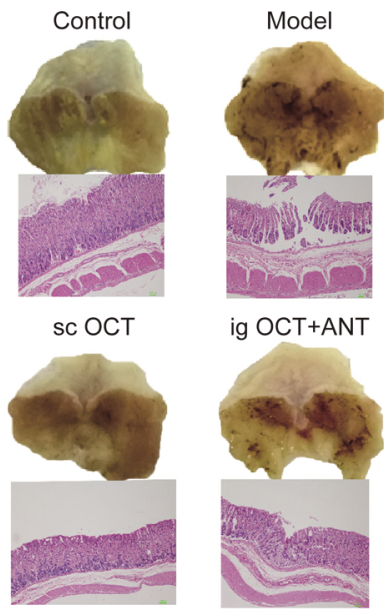

ig OCT+ANT

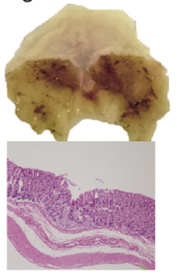

C

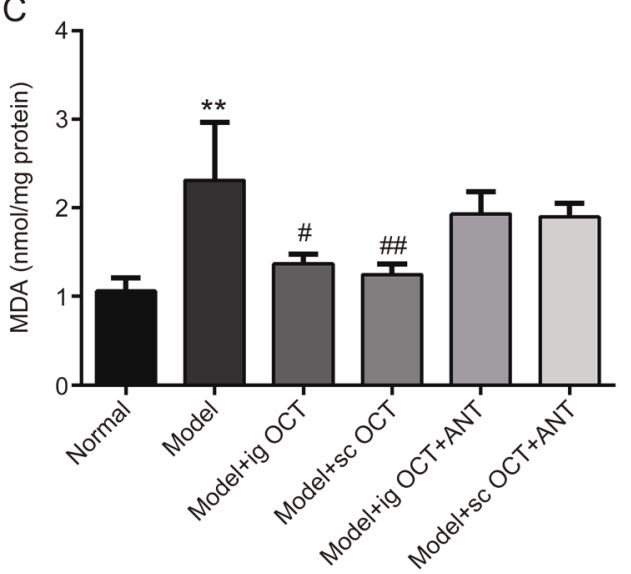

B

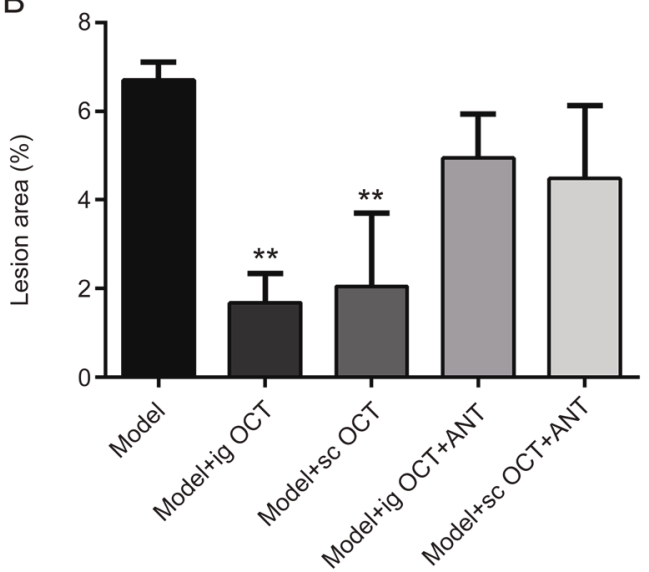

D

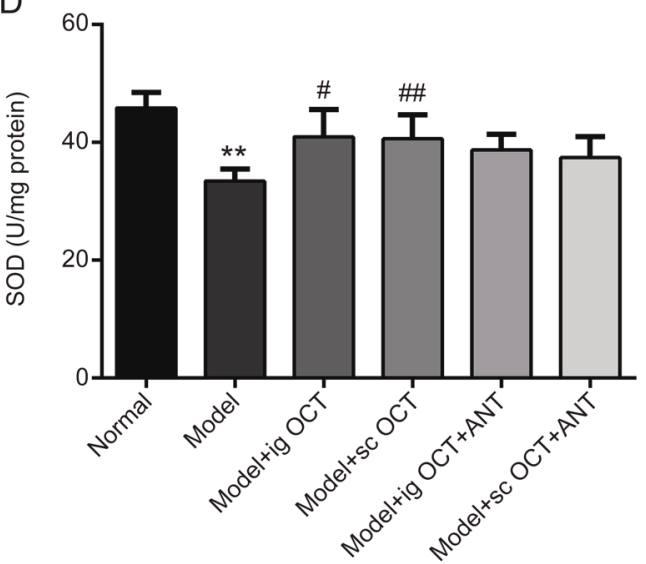

Figure 6. The Influence of SSTRs on the protective effects of OCT in WIRS-mice. (A) Images of mouse stomachs and pathological sections; (B) Lesion areas (\%); (C) MDA levels; (D) SOD levels. ${ }^{* *} P<0.01$ vs normal group. ${ }^{\#} P<0.05,{ }^{\# \#} P<0.01$ vs model group.

injection and direct infusion) due to their poor stability in the gastrointestinal tract and low bioavailability after oral administration $^{[15,30]}$. However, the injection administration regimens adversely impact patient quality of life in many chronic conditions $^{[16]}$. OCT was the first synthetic biologically stable somatostatin analogue; it was introduced into clinical practice after its discovery in $1979^{[31]}$. The necessity of developing an oral formulation of OCT can be summarized as follows: (i) Oral formulations of OCT are beneficial to its clinical application via improving patient compliance. (ii) The clinical safety oral dosage forms was significantly higher than that of injection preparations. (iii) In addition to the convenience of storage and transportation, the oral formulation could effectively avoid the high solubility requirement of the injection preparation. In the present study, the feasibility of developing an oral formulation of OCT was systematically investigated from pharmacokinetic and pharmacodynamic perspectives to improve therapeutic compliance and reduce the risk of adverse reactions.

Initially, the pharmacokinetics of OCT in rats was studied to investigate the feasibility of developing an oral dosage form for OCT. The results suggested that the OCT could enter the systemic circulation; however, its absolute bioavailability was extremely low in rats $(<0.5 \%)$. Factors causing low bioavailability were subsequently explored to reveal whether it would be possible to enhance the feasibility of developing oral formulations via improving its bioavailability. First, the uptake and transport characteristics of OCT were studied in Caco-2 and MDCK cells. As shown in Supplementary Figure S1A and $\mathrm{S} 1 \mathrm{~B}$, OCT could permeate the Caco-2 cell membrane and enter into cells, and the intracellular concentrations of OCT increased with increasing incubation time and levels. However, the intracellular concentrations were much lower than the extracellular concentrations $(20 \mu \mathrm{g} / \mathrm{mL})$. Additionally, permeability data in combination with other in vitro parameters could be used to predict the oral pharmacokinetics of a compound in vivo. The P-gp-mediated transport of the probe digoxin $(5 \mu \mathrm{mol} / \mathrm{L})$ and OCT across Caco-2 cell monolayers in the absorptive $(\mathrm{AP} \rightarrow \mathrm{BL})$ and secretory $(\mathrm{BL} \rightarrow \mathrm{AP})$ directions and the corresponding ER values are shown in Supplementary Figure S1C. Clearly, OCT could be considered a "permeability-limited" drug, since both the $P_{\text {app(AP-BL) }}$ and $P_{\text {app(BL-AP) }}$ values of OCT were approximately $2 \times 10^{-7} \mathrm{~cm} / \mathrm{s}$. Moreover, the classical P-gp inhibitor verapamil could decrease the ER value of OCT from 1.35 to 0.98 , which suggested that OCT might be 

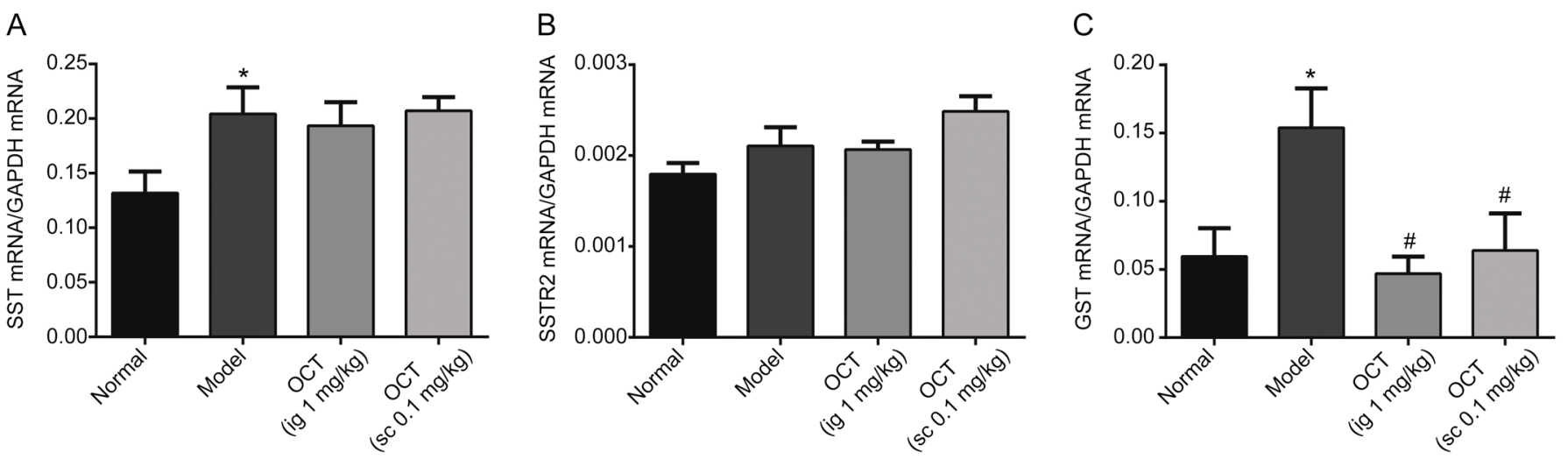

D

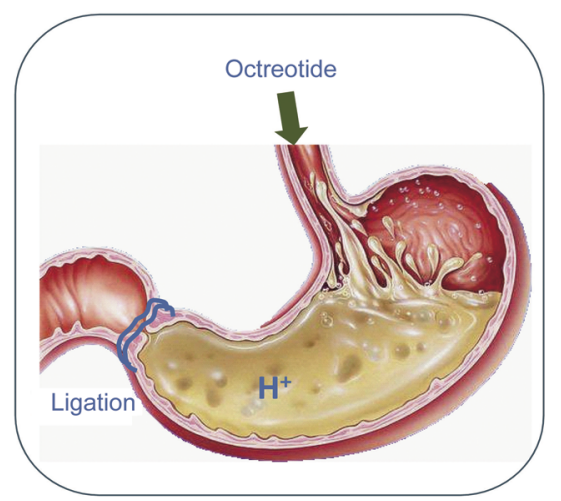

$\mathrm{F}$

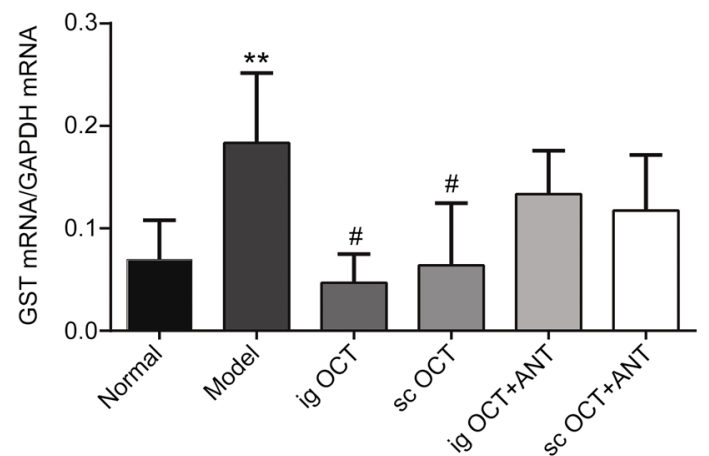

E

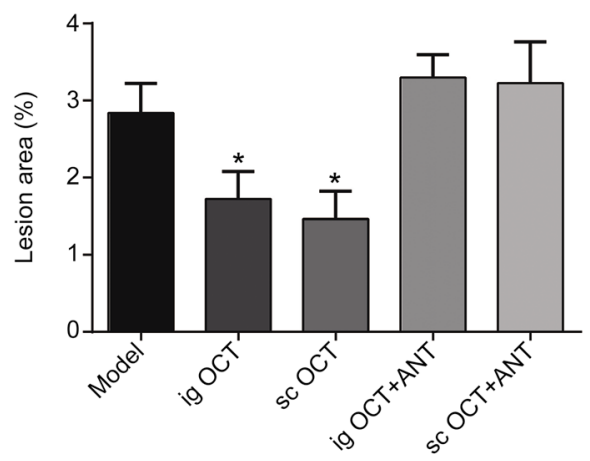

G

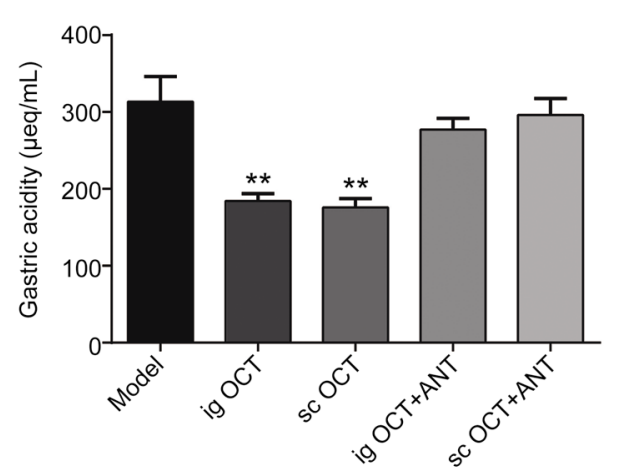

Figure 7. Protective mechanism of OCT in WIRS animals. (A) The effects of OCT on the expression of SST. ${ }^{*} P<0.05$; (B) The effects of OCT on the expression of gastrin; (C) The effects of OCT on the expression of SSTR2. ${ }^{*} P<0.05$ vs normal group. ${ }^{\#} P<0.05$ vs model group; (D) A pyloric ligationinduced ulcer model; (E) The lesion areas (\%) of rat stomachs. ${ }^{*} P<0.05$; (F) Gastrin levels. ${ }^{* *} P<0.01$ vs normal group. ${ }^{\#} P<0.05$ vs model group; (G) Gastric acid pH levels. ${ }^{* *} P<0.01$.

a weak substrate of P-gp. MDCK-wild and MDR1-MDCK cell models were used to further validate the above conclusions. As shown in Supplementary Figure S1D, the ER value of OCT in MDR1-MDCK cells was much lower than that of digoxin, and verapamil in MDR1-MDCK cells could decrease the efflux ratio from 3.44 to 0.89 . In MDCK-wild cells, a cell line lacking P-gp, verapamil could not affect the efflux ratio of either digoxin or OCT. The results above fully confirm that OCT is a weak substrate of P-gp. Thus, P-pg may cause the low bioavailability of OCT to a limited extent, but it is not the main factor. Finally, the stability of OCT in simulated gastric fluid (SGF, pH 1.5) and simulated intestinal fluid (SIF, pH 6.8) was investigated to further elucidate the factors causing its low bioavailability. As shown in Supplementary Figure S2, OCT was stable in SGF, and 50\% of OCT was degraded in SIF within $2 \mathrm{~h}$. The results above confirm that a variety of factors lead to the low bioavailability of OCT, and improving absorption is therefore an extremely challenging task. Over the past several decades, various measures, including increasing lipophilicity and transiently opening tight cell junctions with sinomenine/alkylsaccharides, have been adopted to increase the paracellular absorption of $\mathrm{OCT}^{[14-16]}$. These measures have only succeeded in increasing the bioavailability from $0.5 \%$ to $1.5 \%$ and could not thoroughly improve the low bioavail- 
ability of OCT. Thus, it appears impossible to develop an oral dosage formulation of OCT based on its bioavailability.

Tissue-specific distribution as a basis for drug development has attracted increasing attention in recent years. Given that OCT has often been used clinically in the treatment of gastrointestinal-related diseases, the gastrointestinal tract was determined to be the target organ of OCT. Excitingly, the distribution of OCT in rat tissues indicated that OCT was specifically enriched in the gastrointestinal tract after ig administration, and the concentrations in the stomach, duodenum, jejunum, and ileum were significantly higher than those in other tissues (Figure 1B). To further elucidate the tissue-specific distribution characteristics of OCT, the spatial-distribution characteristics of OCT in the rat stomach after intravenous administration was visualized via an iMScope. These results indicated that the amount of OCT in the gastric mucosal layer was markedly higher than that in the musculature layer postintravenous dose (Figure 3). Moreover, the tissue-specific distribution of OCT in rat tissues at 10, 20, 40, 60, 120, 240 and $360 \mathrm{~min}$ after ig administration of octreotide at a dose of 50 $\mathrm{mg} / \mathrm{kg}$ was determined by iMScope in a previous study ${ }^{[19]}$. The concentrations of OCT in the gastrointestinal tract were shown to be much higher than those in other tissues post-oral treatment. Thus, OCT could specifically distribute to the gastric mucosa with either ig or iv administration. According to previous reports, SST peptides could exert a series of biological effects via binding to the SSTRs expressed in the target tissues, and the therapeutic effects of somatostatin analogs, such as OCT and lanreotide, depend on the expression of specific somatostatin receptors on the target cells ${ }^{[25,32,33]}$. To date, no study has examined the effect of SSTRs on the pharmacokinetics of somatostatin analogs. Herein, we investigated whether somatostatin receptors mediate the tissue-specific distribution of OCT in vitro (HCT116, Caco-2 and GES-1 cells) and in vivo (stomach, duodenum, jejunum, ileum and colon). The results revealed that the expression of SSTR2 was significantly higher than that of SSTR3 and SSTR5 in rat stomachs, and the SSTR2 contributes to the tissue-specific distribution of OCT.

More importantly, the protective effects of OCT in GMI was studied to investigate the feasibility of developing an oral dosage form for OCT. To the best of our knowledge, this is the first pharmacodynamic study of OCT given via oral administration. The results confirmed that OCT could exert a protective role in gastric mucosal injury in WIRS-model animals via both ig and sc administration, and an antagonist of SSTR2 could dramatically attenuate the pharmacological effects of OCT. Moreover, an additional GMI model (rats given a high dose of alcohol) was used to verify the protective effects of OCT post-oral administration, and the results are shown in Supplementary Figure S3. Clearly, there was accumulated blood in the stomach cavity in the model rats. When the ig administration doses were 0.1 and $1.0 \mu \mathrm{g} / \mathrm{kg}$, the lesion areas of the OCT-treated rat were significantly lower than that of model group mice $(P<0.05)$, and the dosage and efficacy showed a "U-shaped" relationship. More importantly, the potencies of the ig and sc routes were comparable. These results suggested that ig administration of OCT could exert similar protective effects for GMI as sc administration, and SSTR2 had a direct impact on exerting its efficiency. Finally, a PLIU model was established to preliminarily explore the protective mechanism of OCT, and the results suggested that OCT could reduce the secretion of gastric acid via down-regulating the gastrin level to exert a protective role in gastric injury.

In conclusion, the tissue-specific distribution and excellent protective effects against GMI after ig administration made it possible to develop an oral form of OCT. Moreover, the high expression of SSTR2 in the gastrointestinal tract contributes to the tissue-specific distribution and therapeutic effects of OCT. Given the tissue-specific distribution characteristics of OCT mediated by SSTR2 and the over-expression of SSTR2 on various tumor cells, oral forms of OCT may also be relevant for use in other clinical indications, including gastroenteropancreatic neuroendocrine neoplasms and pituitary adenoma. The present study not only supports the further development and clinical application of octreotide but also provides a novel avenue for the development of oral formulations for other peptide drugs.

\section{Acknowledgements}

This study was supported by the National Natural Science Foundation (81374054, 81573559, and 81530098), the Natural Science Foundation of Jiangsu Province (BK20171395), and the Outstanding Youth Fund of the State Key Laboratory of Natural Medicines (SKLNMZZJQ201602).

\section{Supplementary information}

The abbreviations are summarized in Table S3, and supplementary information is available on the website of Acta Pharmacologica Sinica.

\section{References}

1 Lamberts SW, Krenning EP, Reubi JC. The role of somatostatin and its analogs in the diagnosis and treatment of tumors. Endocr Rev 1991; 12: 450 .

2 Sun L, Coy DH. Somatostatin and its Analogs. Curr Drug Targets 2016; 17: 529-37.

3 Liu HL, Huo L, Wang L. Octreotide inhibits proliferation and induces apoptosis of hepatocellular carcinoma cells. Acta Pharmacol Sin 2004; 25: 1380-6.

4 Oberg KE, Lamberts SW. Somatostatin analogues in acromegaly and neuroendocrine tumours: past, present and future. Endocr Relat Cancer 2016; 23: R551-66.

5 Wang L, Huang X, Chai Y, Zou L, Chedrawe M, Ding Y. Octreotide inhibits the proliferation of gastric cancer cells through P300-HAT activity and the interaction of ZAC and P300. Oncol Rep 2017; 37: 2041-8.

6 Sener G, Paskaloglu K, Kapucu C, Cetinel S, Contuk G, AyanoğluDülger $\mathrm{G}$. Octreotide ameliorates alendronate-induced gastric injury. Peptides 2004; 25: 115-21.

7 Sun H, Zou S, Candiotti KA, Peng Y, Zhang Q, Xiao W, et al. Octreotide attenuates acute kidney injury after hepatic ischemia and reperfusion by enhancing autophagy. Sci Rep 2017; 7: 42701.

8 Ezzat S, Snyder PJ, Young WF, Boyajy LD, Newman C, Klibanski A, et al. Octreotide treatment of acromegaly. A randomized, multicenter study. 
Ann Inter Med 1992; 117: 711-8.

9 Hofland LJ, Lamberts SW. The pathophysiological consequences of somatostatin receptor internalization and resistance. Endocr Rev 2003; 24: 28.

10 Vance ML, Harris AG. Long-term treatment of 189 acromegalic patients with the somatostatin analog octreotide. Results of the International Multicenter Acromegaly Study Group. Arch Intern Med 1991; 151: 1573-8.

11 Lancranjan I, Bruns C, Grass P, Jaquet P, Jervell J, Kendall-Taylor P, et al. Sandostatin $\operatorname{LAR}^{\oplus}$ : pharmacokinetics, pharmacodynamics, efficacy, and tolerability in acromegalic patients. Metabolism 1995; 44: 18-26.

12 Soudry-Kochavi L, Naraykin N, Nassar T, Benita S. Improved oral absorption of exenatide using an original nanoencapsulation and microencapsulation approach. J Control Release 2015; 217: 202-10.

13 Mendes M, Soares HT, Arnaut LG, Sousa JJ, Pais AACC, Vitorino C. Can lipid nanoparticles improve intestinal absorption? Int J Pharm 2016; 515: 69.

14 Biron E, Chatterjee J, Ovadia O, Langenegger D, Brueggen J, Hoyer D, et al. Improving oral bioavailability of peptides by multiple $\mathrm{N}$-methylation: somatostatin analogues. Angew Chem Int Ed Engl 2008; 47: 2595-9.

15 Li Y, Duan Z, Yan T, Zhen L, Wang Q. A novel perspective and approach to intestinal octreotide absorption: sinomenine-mediated reversible tight junction opening and its molecular mechanism. Int J Mol Sci 2013; 14: 12873-92.

16 Maggio ET, Grasso P. Oral delivery of octreotide acetate in Intravail ${ }^{\circledR}$ improves uptake, half-life, and bioavailability over subcutaneous administration in male Swiss webster mice. Regul Pept 2011; 167: 233.

17 Chen T, Song X, Gong T, Fu Y, Yang L, Zhang Z, et al. nRGD modified lycobetaine and octreotide combination delivery system to overcome multiple barriers and enhance anti-glioma efficacy. Colloids Surf B Biointerfaces 2017; 156: 330.

18 Wang Q, Liang Y, Rao T, Xie L, Ye W, Fu H, et al. PK study of octreotide based on LC-MS/MS combining protein precipitation and impurity extraction technique. Bioanalysis 2015; 7: 885-94.

19 Rao T, Shao Y, Hamada N, Li Y, Ye H, Kang D, et al. Pharmacokinetic study based on a matrix-assisted laser desorption/ionization quadrupole ion trap time-of-flight imaging mass microscope combined with a novel relative exposure approach: A case of octreotide in mouse target tissues. Anal Chim Acta 2017; 952: 71-80.

20 Liang Y, Zhou Y, Zhang J, Rao T, Zhou L, Xing R, et al. Pharmacokinetic compatibility of ginsenosides and Schisandra lignans in Shengmaisan: from the perspective of P-glycoprotein. PLoS One 2014; 9 : e98717.

21 Zhou S, Feng X, Kestell P, Paxton JW, Baguley BC, Chan E. Transport of the investigational anti-cancer drug 5,6-dimethylxanthenone-4acetic acid and its acyl glucuronide by human intestinal Caco- 2 cells. Eur J Pharm Sci 2005; 24: 513-24.

22 Bustin SA, Benes V, Garson JA, Hellemans J, Huggett J, Kubista M, et al. The MIQE guidelines: minimum information for publication of quantitative real-time PCR experiments. Clin Chem 2009; 55: 61122.

23 Martins NB, Chaput KJ, Stawicki SP, Modi R. Octreotide as an adjunct in the management of arterial gastrointestinal bleeding: should it be considered in refractory cases of obscure origin? Int J Crit IIIn Inj Sci 2017; 7: 8-11.

24 Nie SN, Qian XM, Wu XH, Yang SY, Tang WJ, Xu BH, et al. Role of TFF in healing of stress-induced gastric lesions. World J Gastroenterol 2003; 9: 1772-6.

25 Nakashima M, Takano K, Matsuno A. Analyses of factors influencing the acute effect of octreotide in growth hormone-secreting adenomas. Endocr J 2009; 56: 295-304.

26 Miller GM, Alexander JM, Bikkal HA, Katznelson L, Zervas NT, Klibanski A. Somatostatin receptor subtype gene expression in pituitary adenomas. J Clin Endocrinol Metab 1995; 80: 1386-92.

27 Pisarek H, Pawlikowski M, Marchlewska M, Minias R, Winczyk K. An immunohistochemical investigation of the expression of somatostatin receptor subtypes - should therapeutic trials be performed to determine the efficacy of somatostatin analogs in treating advanced thyroid malignances? Exp Clin Endocrinol Diabetes 2015; 123: 3426.

28 Wang $\mathrm{T}$, Leng $\mathrm{YF}$, Zhang $\mathrm{Y}$, Xue $\mathrm{X}$, Kang $\mathrm{YQ}$, Zhang $\mathrm{Y}$. Oxidative stress and hypoxia-induced factor $1 \alpha$ expression in gastric ischemia. World $J$ Gastroenterol 2011; 17: 1915-22.

29 Ceglia L, Harris SS, Rasmussen HM, Dawson-Hughes B. Activation of the calcium sensing receptor stimulates gastrin and gastric acid secretion in healthy participants. Osteoporos Int 2009; 20: 71-8.

30 Thorne RG, Frey WH 2nd. Delivery of neurotrophic factors to the central nervous system: pharmacokinetic considerations. Clin Pharmacokinet 2001; 40: 907-46.

31 Colao A, Auriemma RS, Pivonello R, Kasuki L, Gadelha MR. Interpreting biochemical control response rates with first-generation somatostatin analogues in acromegaly. Pituitary 2016; 19: 235-47.

32 Fougner SL, Borota OC, Berg JP, Hald JK, Ramm-Pettersen J, Bollerslev $J$. The clinical response to somatostatin analogues in acromegaly correlates to the somatostatin receptor subtype2a protein expression of the adenoma. Clin Endocrinol (Oxf) 2008; 68: 458-65.

33 Yu B, Zhang Z, Hao S, Chi Y, Shi C, Miao X. Clinical importance of somatostatin receptor 2 (SSTR2) and somatostatin receptor 5 (SSTR5) expression in thyrotropin-producing pituitary adenoma (TSHoma). Med Sci Monit 2017; 23: 1947. 